\title{
PERCEPÇÃO DOS GESTORES FINANCEIROS DAS PEQUENAS E MÉDIAS EMPRESAS QUANTO AO CUSTO DE CAPITAL
}

\section{PERCEPTION OF THE FINANCIAL MANAGERS OF THE SMALL AND MIDDLE BUSINESS WITH RELATIONSHIP AT THE COST OF CAPITAL}

\author{
Márcio André Veras Machado
}

Mestre em Administração; Professor do Departamento de Administração da Universidade Federal da Paraíba - UFPB; Av. Epitácio Pessoa, 3883, apt ${ }^{\circ} 1602$ C, Miramar, Cep: 58.032000; Telefone: (83) 3226-5030; e-mail: marciomachado@ hs24.com.br

\section{Márcia Reis Machado}

Mestre em Contabilidade; Professora do Departamento de Finanças e Contabilidade da Universidade Federal da Paraíba - UFPB; Av. Epitácio Pessoa, 3883, apt ${ }^{\circ} 1602$ C, Miramar, Cep: 58.032-000; Telefone: (83) 3226-5030; e-mail: marciareis@ hs24.com.br

\section{Aldo Leonardo Cunha Callado}

Mestre em Administração; Professor do Departamento de Finanças e Contabilidade da Universidade Federal da Paraíba - UFPB; Rua Estudante José Klean Pereira Moura, 55, apt ${ }^{\circ}$ 1101, Bessa, Cep: 58.037-220. Telefone: (083) 3246-0373; e-mail:aldocallado@ yahoo.com.br

\section{RESUMO}

Este artigo, de cunho exploratório-descritivo, tem como objetivo analisar o grau de percepção dos gestores financeiros das pequenas e médias empresas quanto ao custo de capital. Foram coletados os dados de 27 empresas, pertencentes a 10 setores da economia. O método escolhido para coleta de dados foi a entrevista pessoal estruturada em um roteiro previamente elaborado. Constatou-se que a maioria dos entrevistados não conhece o custo do capital próprio. Os que conhecem mensuram, em sua maioria, como a taxa mínima de rentabilidade exigida, mensurada pelo custo de oportunidade perdida. No que diz respeito ao custo do capital de terceiros, grande parte conhece e foi unânime em afirmar que o custo do capital de terceiros é explícito e já vem definido pelas instituições financeiras, em seus respectivos contratos. Observou-se que, dos gestores entrevistados que afirmaram conhecer o custo de capital próprio e de terceiros, grande parte ocupava o cargo de diretoria, possuía formação em contabilidade ou engenharia, tinham mais de 15 anos de experiência na função, tinham acima de 40 anos de idade, trabalhavam em empresas com 21 anos ou mais de existência no mercado e era do sexo masculino.

Palavras-chave: Custo de Capital Próprio, Custo de Capital de Terceiros, Pequenas e Médias Empresas.

\begin{abstract}
This article has as purpose to analyze the degree of the financial managers' perception among small and middle organizations about the capital cost. The data were collected within 27
\end{abstract}


companies in 10 sections of the Brazilian economy. The method chosen for data collection relies greatly on personal interviews based on route previously elaborated. The interviews demonstrated that most of the interviewees even does not know about the cost of equity. The ones who know about it, in its majority, measure like as the minimum rate of profitability, measured for the cost of lost opportunity. In the regard of the cost of debt, most of them know and were unanimous to confirm that the cost of debt is explicit and it already comes defined by the financial institutions, in its contracts. It was observed that among the managers interviewed which affirmed to know the cost of equity and cost of debt, the great part were in the management position, had college degree in accounting or engineering,, had more than 15 years of experience in these functions, had over 40 years, worked within companies 21 years old and over in the market, and were basically male.

Key-words: Cost of Equity, Cost of Debt, Small and Middle Business.

\section{INTRODUÇÃO}

O capital é um fator de produção necessário e, como qualquer outro fator, ele tem um custo. Portanto, o capital, tanto próprio como de terceiros, não é gratuito, tendo em vista que se esses fundos não forem empregados dentro da empresa, certos custos associados ao empréstimo podem ser evitados e o capital liberado pode ser empregado em outra alternativa mais lucrativa. O custo de capital é uma das variáveis principais e mais importantes no estudo na estrutura de capital e possui fundamental importância na tomada de decisão, tanto sob os aspectos de financiamentos como de investimento. Destaca-se sua importância, também, no processo de determinação do valor agregado, ou seja, de verificação da criação ou destruição de valor por parte das empresas.

No que diz respeito às decisões de investimento, o custo de capital estabelece um limite inferior ou mínimo, contra o qual todos os investimentos devem ser comparados. Nas decisões de financiamento, o custo de capital está relacionado com a composição da estrutura de capital, isto é, para qualquer quantia total de capital requerido, há um equilíbrio entre capital próprio e de terceiros que minimizará o custo do capital global, maximizando o valor da empresa, conseqüentemente, a riqueza dos acionistas ou proprietários.

Diversos fatores afetam o custo de capital da empresa. Alguns estão além do controle da empresa, mas outros são influenciados pelas políticas de financiamento e de investimento corporativos.

Os dois fatores mais importantes que estão além do controle direto da empresa são o nível das taxas de juros e os impostos. Se as taxas de juros da economia se elevam, o custo de capital de terceiros aumenta, porque as empresas precisarão pagar uma taxa de juros mais alta 
aos proprietários de títulos para obter capital de terceiros. Com relação aos impostos, as empresas também não têm controle sob esta variável, pois diz respeito à política tributária do governo, sendo difícil para a empresa prever variações nas alíquotas dos impostos.

Por outro lado, uma empresa pode controlar seu custo de capital por meio de sua política de estrutura de capital, de sua política de dividendos e de sua política de investimento.

Tendo em vista que o custo do capital é importante tanto para as decisões de investimento, como para as decisões de financiamento, funcionando como base para a tomada de decisões financeiras, pergunta-se: será que os gestores financeiros das pequenas e médias empresas conhecem o custo de capital de suas empresas?

Diante do exposto, esse artigo, de cunho exploratório-descritivo, tem como objetivo analisar o grau de percepção dos gestores financeiros das pequenas e médias quanto ao custo de capital.

\section{REVISÃO DA LITERATURA}

\subsection{Custo de Capital}

A palavra Capital possui diversos e variados significados. Archer e D'Ambrosio (1969, p.253) definem o termo capital como "o conjunto dos recursos sobre os quais a empresa exerce certo controle e que são utilizados na obtenção de lucros. O termo capital pode significar o conjunto dos ativos utilizados pela empresa, sendo os ativos totais equiparados ao capital total".

Van Horne (1979, p.70) define custo de capital como sendo "a taxa de retorno de um projeto cuja aceitação não altera o preço da ação. Neste sentido, o custo de capital constituirá a taxa de retorno exigida para que se justifique a execução de um projeto".

Para Gitman (1997, p.382), “o custo de capital pode ser definido como a taxa de retorno que a empresa precisa obter sobre os seus projetos de investimentos, para manter o valor de mercado de suas ações e atrair os recursos necessários para a empresa".

As subdivisões do ativo total também são conhecidas como capital, sendo normalmente acrescido de um adjetivo que melhor o descreve, como capital circulante e capital fixo (ARCHER e D'AMBROSIO, 1969).

$\mathrm{Na}$ teoria econômica, o termo capital denota um fator de produção, representando, segundo Leite (2000), a capacidade produtiva instalada, envolvendo máquinas, equipamentos 
e instalações produtivas agrícolas, industriais ou de serviços, bem como toda a infra-estrutura econômica usada pelos sistemas de transportes, comunicações, educação, saúde e segurança de um país.

A contabilidade trata, quando da elaboração das demonstrações financeiras, o direito dos proprietários como capital, sendo mais conhecido como capital social, agrupando os direitos dos credores no Passivo Exigível.

A palavra capital pode significar também recursos monetários, quando usados no sentido de obtenção de capital.

O capital também pode ser considerado como sendo o conjunto de direitos exercidos sobre os ativos das empresas. De acordo com esta definição, o capital encontra-se dividido em duas categorias, mutuamente exclusivas e exauríveis, quais sejam: capital próprio e capital de terceiros.

Tanto o capital próprio como o capital de terceiros possui custos de natureza implícita e explicita. Os custos de natureza implícita estão relacionados com o custo de oportunidade, que segundo Pindyck e Rubinfeld (1994, p.257) "são os custos associados com as oportunidades que serão deixadas de lado, caso a empresa não empregue seus recursos em sua utilização de maior valor". Eles representam usos alternativos para os fundos em consideração, portanto representam o custo da melhor oportunidade perdida acessível à empresa (MACHADO, 2002).

Para que se possa mensurar o custo total de capital de uma empresa, é necessário, antes de tudo, considerar os custos dos diversos métodos específicos de financiamento, isto é, saber o custo específico de cada componente da estrutura de capital. Segundo Gitman (1997), o custo específico de cada fonte de financiamento é o custo de obtenção dos fundos hoje, após o imposto de renda, e não o custo histórico, baseado na estrutura de financiamento atual da empresa. A análise dos custos específicos de cada componente da estrutura de capital das empresas será feita nos itens 2.2 e 2.3 .

\subsection{Custo de Capital Próprio}

O custo de capital próprio representa o segmento de estudo mais complexo das finanças corporativas, assumindo diversas hipóteses e abstrações teóricas em seus cálculos (ASSAF NETO, 2003). 
Para Van Horne (1979, p.73), o custo do capital próprio é o de determinação mais difícil. Em termos teóricos, poderá ser definido pela taxa mínima de retorno a ser obtida pela empresa na parcela financiada mediante capital próprio, em um dado projeto, para manter constante o preço de mercado da ação.

Esta taxa mínima está relacionada com o custo da melhor oportunidade acessível perdida pelos acionistas, pois, para se investir em uma empresa, o acionista está abrindo mão de aplicar seu dinheiro no mercado financeiro, e por isso quer ter no mínimo a expectativa de conseguir esse retorno nas ações da empresa (SANVICENTE e MINARD, 1999, p.2).

$\mathrm{Na}$ presente pesquisa, o capital próprio das empresas encontra-se dividido basicamente em três fontes específicas: as ações preferenciais, as ações ordinárias e os lucros retidos. Essas fontes específicas de capital próprio diferem substancialmente no que diz respeito à mensuração de seus custos, uns por serem mais complexos, como é o caso dos lucros retidos e ações ordinárias, e outros por serem mais simples, como é o caso das ações preferenciais. A ação ordinária é, tipicamente, a forma mais dispendiosa de capital, seguida pelos lucros retidos e ações preferenciais, respectivamente.

Desta forma, o custo de capital próprio pode ser mensurado conforme Equação 1 (WESTON e BRIGHAM, 2000):

$$
k_{e}=w \times k_{p}+w \times k_{s}+w \times k_{r} \quad \text { Eq. } 1
$$

Onde: W - Proporção de cada capital no total de capital próprio; $k_{e}$ - Custo do capital próprio; $k_{p}$ - Custo de capital da ação preferencial; $k_{s}$ - Custo de capital da ação ordinária; e $k_{r}$ - Custo do capital dos lucros retidos.

\subsubsection{Custo da Ação Preferencial}

A ação é um título de participação e corresponde à menor parcela em que se pode dividir o capital social de uma empresa. De acordo com Lameira (2001), as ações preferenciais são aquelas que outorgam aos seus detentores direitos de recebimento de dividendos mínimos, se fixados no estatuto, e preferência em relação às ações ordinárias em casos de liquidação da companhia. Porém, não têm direito de decidir os destinos da companhia. 
De acordo com o artigo 17 da lei 6.404/76, as preferências e vantagens das ações preferenciais são: prioridade na distribuição de dividendos; prioridade no reembolso do capital, com prêmio ou sem ele; na acumulação das vantagens acima.

O custo de capital da ação preferencial é obtido dividindo-se o dividendo anual preferencial pelos recebimentos líquidos da venda da ação preferencial, conforme mostra a Equação 2 (WESTON e BRIGHAM, 2000). Os recebimentos líquidos representam o montante de dinheiro a ser recebido, livre de quaisquer despesas de emissão e venda, exigidas para se negociar a ação.

$$
k_{p}=\frac{D_{p}}{N_{p}}
$$

Onde: $k_{p}$ - Custo de capital da ação preferencial; $D_{p}$ - Dividendo anual preferencial; $N_{p}$ - Recebimentos líquidos da venda da ação preferencial.

\subsubsection{Custo da Ação Ordinária}

O custo da ação ordinária é a taxa pela qual os investidores descontam os dividendos esperados da empresa para determinar o valor de suas ações (GITMAN, 1997, p.391).

A mensuração do custo da ação ordinária é o que apresenta maiores dificuldades, basicamente por dois fatores: dificuldade na previsão dos lucros futuros que se converte em dividendos e dificuldade de previsão dos preços das ações.

Damodaran (1997), Ross et. al. (2001), Gitman (1997), Brigham e Houston (1999), Assaf Neto (2003), Copeland et. al. (2002), dentre outros, apresentam três métodos para se determinar o custo das ações ordinárias: a abordagem do modelo de precificação de ativos de capital (CAPM), a abordagem rentabilidade de título mais prêmio pelo risco e a abordagem da rentabilidade de dividendos mais taxa de crescimento ou abordagem do fluxo de caixa descontado (FLCD).

O CAPM teve seu marco inicial com a publicação dos trabalhos de Sharpe (1964), Lintner (1965) e Treynor (1961). O CAPM estabelece que o retorno esperado de um ativo é função linear do ativo livre de risco, do risco sistemático do ativo (Beta) e do prêmio de risco da carteira de mercado em relação ao ativo livre de risco, conforme Equação 3. O CAPM diz que o investidor quer ser remunerado apenas pelo risco de mercado ao qual está exposto, e que este risco pode ser medido pelo coeficiente Beta, cujo valor depende de como os retornos 
do ativo variam em conjunto com os retornos da carteira de mercado (SANVICENTE E MINARD, 1999).

$$
k_{s}=k_{r f}+\beta_{i} \times\left(k_{m}-k_{r f}\right)
$$

Onde: $k_{s}$ - Custo do capital próprio; $k_{r f}$ - Taxa livre de risco; $b_{i}$ - Coeficiente beta da ação; $k_{m}-$ Retorno da carteira de mercado.

Portanto, para o cálculo do CAPM, faz-se necessário o cálculo de três variáveis fundamentais: a taxa livre de risco, o Beta e o prêmio de risco. A taxa de retorno livre de risco é aquela cujo retorno esperado seria igual ao retorno efetivo, ou seja, aquela em que não há variância no retorno (SILVA, 2005). Como taxa de livre de risco, pode-se utilizar o CDI, poupança, títulos de longo prazo do governo ( $C$ Bond, para títulos brasileiros, $T$ bond, para títulos do governo americano), retorno do mercado de renda fixa, dentre outros. Copeland et. al. (2002) recomendam os $T$ Bond americanos de 10 anos, por aproximar-se dos fluxos de caixa projetados das empresas em que estão sendo avaliadas, por aproximar-se em duração das carteiras baseadas em índices do mercado acionário e por ser menos propensos a mudanças imprevistas na legislação.

O coeficiente Beta é a tendência de uma ação mover-se com o mercado e mede a volatilidade da ação em relação a uma ação média (WESTON E BRIGHAM, 2000). O que se procura medir com este coeficiente é o grau de volatilidade de um título às mudanças no comportamento do mercado, partindo-se do princípio de que todos os títulos tendem a ter os seus preços alterados, em maior ou menor proporção, às alterações do mercado com um todo (ALCÂNTARA, 1981). O Beta representa o resultado da divisão da covariância entre os retornos da carteira de mercado e os retornos do ativo livre de risco pela variância da carteira de mercado, conforme Equação 4 (SHARPE, 1964).

$$
\beta=\frac{\operatorname{Cov}\left(R_{i}, R_{m}\right)}{\sigma^{2}\left(R_{m}\right)}
$$

Onde: $R_{m}$ - É o valor do retorno da carteira de mercado, que pode ser Ibovespa, S \& P 500, FGV-100, dentre outras; $R_{i}$ - é o valor do retorno do ativo i; $\sigma^{2}$ - Variância.

Os analistas que não confiam no uso do CAPM costumam utilizar um procedimento subjetivo para estimar o custo das ações ordinárias. Eles simplesmente somam um prêmio de 
risco à taxa de juros da dívida de longo prazo da própria empresa (WESTON E BRIGHAM, 2000), isto é :

$$
k_{s}=\text { Rentabilidade do título + Prêmio de risco }
$$

Eq. 5

Van Horne (1979) desmembra o prêmio de risco a que se refere a Equação 5 em dois componentes: o prêmio pelo risco empresarial e o prêmio pelo risco financeiro. O prêmio pelo risco empresarial deve-se à dispersão relativa das probabilidades dos lucros operacionais futuros, enquanto o prêmio pelo risco financeiro é causado pela dispersão dos lucros futuros esperados, disponíveis aos portadores das ações ordinárias, mantido constante o risco empresarial.

A abordagem do fluxo de caixa descontado baseia-se na premissa de que o valor da ação é o valor atual de todos os dividendos previstos que gerará por um período de tempo infinito (DAMODARAN, 1997), isto é:

$$
P_{0}=\sum_{t=1}^{n} \frac{D_{t}}{\left(1+k_{s}\right)^{t}}
$$

Onde: $P_{0}-$ Valor da ação $=$ valor atual da série $D_{t} ; D_{t}$ - Dividendo que se espera que seja pago no final do ano t; $K_{s}$ - Taxa de desconto apropriada para o risco assumido pelos fornecedores de capital próprio.

Caso os dividendos cresçam a uma taxa constante g e $K_{s}$ seja maior que g, então a Equação 6 é reduzida à Equação 7 (WESTON E BRIGHAM, 2000), denominada de modelo de gordon:

$$
P_{0}=\frac{D_{1}}{k_{s}-g}
$$

Resolvendo a equação acima para $k_{s}$, obtem-se:

$$
k_{s}=\frac{D_{1}}{P_{0}}+g
$$

Eq. 8

Assim, os investidores esperam receber uma rentabilidade de dividendos, $\frac{D_{1}}{P_{0}}$, mais um ganho de capital, g, para constituir um retorno esperado $k_{s}$, que em equilíbrio é igual ao retorno exigido.

\subsubsection{Custo de Novas Emissões de Ações Ordinárias}


Quando o capital próprio é obtido com a emissão de novas ações, a empresa incorre em despesas que seriam inexistentes quando esse mesmo capital é conseguido com a retenção de lucros. Se uma empresa desejar vender uma nova emissão de ações ordinárias ao público, esses títulos serão oferecidos por um valor inferior ao preço corrente de mercado da ação. Aliado a isto, a emissão das novas ações envolverá despesas com o processo de colocação dessas ações no mercado, que consistem em taxas de subscrição (underwriting).

Devido ao custo de lançamento envolvido na emissão de novas ações ordinárias, o custo dessas novas ações é mais alto que o custo dos lucros retidos.

O custo de novas emissões de ação ordinária pode ser facilmente determinado, especificando-se a redução percentual do preço corrente de mercado que pode ser atribuída a custos de colocação que consistem de taxas de subscrição e deságio e usando-se a expressão para o custo da ação ordinária existente, $K_{s}$, do modelo de Gordon como ponto de partida. Sendo L a redução percentual do preço corrente de mercado, esperada como resultado das despesas com o underwriting e deságio da nova emissão de ações, pode-se exprimir o custo da nova emissão, $k_{e}$, como (WESTON E BRIGHAM, 2000):

$$
k_{s}=\frac{D_{1}}{(1-L) \times P_{0}}+g
$$

Onde: $k_{s}$ - Custo de capital próprio obtido com a emissão de novas ações; L proporção do preço bruto, representando as despesas de emissão. A empresa recebe, em termos líquidos, $P_{0}(1-\mathrm{L})$.

O termo lucros retidos se refere àquela parte dos lucros do ano corrente que não foi distribuída como dividendos e, portanto, está disponível para reinvestimento nos negócios, no presente ano. O termo lucros retidos pode ser interpretado também como o item do balanço patrimonial denominado de lucros acumulados, o qual consiste de todos os lucros retidos pela empresa durante toda a sua existência. A razão para se atribuir um custo de capital aos lucros retidos envolve o princípio do custo de oportunidade.

Os lucros retidos são considerados por muitos autores, dentre eles, Gitman (1997), Van Horne (1979), Archer e D’Ambrosio (1969), como uma emissão de novas ações ordinárias inteiramente subscrita, pois eles aumentam o patrimônio líquido da mesma forma que uma nova emissão de ações ordinárias. Desta forma, considerando-se o custo dos lucros retidos como uma emissão de ações ordinárias subscrita, pode-se supor que o custo dos lucros retidos, $k_{r}$, seja igual ao custo da ação ordinária, $k_{s}$ (WESTON E BRIGHAM, 2000), ou seja: 


$$
k_{r}=k_{s}
$$

Eq. 10

\subsection{Custo de Capital de Terceiros}

O custo de capital de terceiros é a taxa efetiva de juros, isto é, taxa de juros efetivamente paga pelo capital emprestado, além das taxas de serviços, também cobradas pelos intermediários financeiros.

Ao contrário do que acontece com o capital próprio, o capital de terceiros não necessita ser inferido a partir da avaliação do mercado. Ao contrário, o preço direto pago pelo capital de terceiros é explicitamente estabelecido à época do empréstimo sob a forma de condições contratuais relativas à quantia e época de repagamento do principal de dos juros.

O custo do capital de terceiros pode ser calculado de acordo com a Equação 11 (DAMODARAN, 1997), a qual traduz o custo explícito do capital pela taxa de desconto que iguala o valor presente dos pagamentos futuros correspondentes aos juros e principal à importância líquida dos fundos concedidos à empresa.

$$
I_{0}=\frac{C_{1}}{(1+k)}+\frac{C_{2}}{(1+k)^{2}}+\Lambda \Lambda+\frac{C_{n}}{(1+k)^{n}}
$$

Onde: $I_{0}=$ Montante líquido dos fundos recebidos; $C_{t}=$ Saídas de caixa no período t; $\mathrm{k}=$ Custo do capital.

Porém, o custo do capital de terceiros é substancialmente inferior àquele determinado pela Equação 11. A razão para isto é que os juros pagos pelo uso do capital de terceiros são dedutíveis do pagamento do imposto de renda. Efetivamente, o governo paga uma parte do custo de capital de terceiros. Desta forma, deve-se utilizar o custo do capital de terceiros líquido de impostos, uma vez que a administração financeira está interessada no fluxo de caixa líquido. O custo de capital de terceiros é calculado conforme mostra a Equação 12:

$$
k_{i}=k \times(1-t)
$$

Onde: $k_{i}$ - Custo do capital de terceiros, depois de deduzidos os impostos; $\mathrm{k}$ - Taxa de desconto; $\mathrm{t}$ - Alíquota do imposto de renda.

\section{METODOLOGIA}

\subsection{Caracterização da Pesquisa}


Para a classificação da pesquisa, tomou-se como base a taxonomia desenvolvida por Vergara (2000), que a qualifica em relação a dois aspectos: quanto aos fins e quanto aos meios. Quanto aos fins, esta pesquisa é exploratória e descritiva. Exploratória porque procurou-se ampliar o conhecimento sobre custo de capital e descritiva porque procurou-se descrever o grau de percepção dos gestores financeiros das pequenas e médias empresas quanto ao custo de capital.

Quanto aos meios, esta pesquisa é de campo, porque foi realizada nas pequenas e médias empresas da cidade de João Pessoa/PB, onde se coletou os dados para a elaboração da presente pesquisa.

\subsection{Universo e Amostra}

O universo da pesquisa foi constituído pelas pequenas e médias indústrias de transformação (empregando de 20 a 499 funcionários, conforme critério estabelecido pelo SEBRAE) localizadas na cidade de João Pessoa/PB, cadastradas na Federação das Indústrias do Estado da Paraíba - FIEP, pertencentes à iniciativa privada e que concordaram em participar da pesquisa, totalizando 57 empresas.

Das 57 empresas consultadas, excluiu-se 30: 17 por não concordarem em participar da pesquisa e/ou fornecer os dados necessários para realização do estudo; seis por não terem sido localizadas; cinco por encontrarem-se desativadas; uma por ser empresa pública; uma por ter transferido suas atividades para outro Estado. Portanto, foram coletados dados de 27 empresas.

\subsection{Coleta dos Dados}

O método escolhido para a coleta de dados foi a entrevista pessoal estruturada em um roteiro previamente elaborado. As entrevistas tinham por finalidade solicitar aos diretores e/ou gerentes financeiros das empresas o preenchimento de um questionário que serviu de base para a análise dos dados. O questionário encontra-se dividido em duas partes. A primeira parte, que identificou a empresa, versa sobre o setor da empresa, linha de produção, perfil dos entrevistados e número de empregados. A segunda parte diz respeito à percepção dos entrevistados quanto ao custo de capital. 


\subsection{Método de Análise}

Para análise dos dados, fez-se uso da estatística descritiva e do teste Exato de Fisher. O teste exato de Fisher é aconselhável para amostras menores que 20 e entre 20 e 40, com 1 grau de liberdade, desde que a menor freqüência esperada seja inferior a 5. (SIEGEL, 1975). Para isso, fez-se uso do pacote estatístico SPSS - Statistical Package for the Social Sciences.

No presente artigo, serão testadas as seguintes hipóteses, ao nível de significância de 5\%: 1. $H_{0}$ : Não há relação entre o cargo ocupado e o conhecimento do custo de capital próprio, $H_{1}$ : Há relação entre o cargo ocupado e o conhecimento do custo de capital próprio; 2. $H_{0}$ : Não há relação entre o cargo ocupado e o conhecimento do custo de capital de terceiros, $H_{1}$ : Há relação entre o cargo ocupado e o conhecimento do custo de capital de terceiros; 3. $H_{0}$ : Não há relação entre possuir curso superior e o conhecimento do custo de capital próprio, $H_{1}$ : Há relação entre possuir curso superior e o conhecimento do custo de capital próprio; 4. $H_{0}$ : Não há relação entre possuir curso superior e o conhecimento do custo de capital de terceiros, $H_{1}$ : Há relação entre possuir curso superior e o conhecimento do custo de capital de terceiros; 5. $H_{0}$ : Não há relação entre a experiência na função e o conhecimento do custo de capital próprio, $H_{1}$ : Há relação entre a experiência na função e o conhecimento do custo de capital próprio; 6. $H_{0}$ : Não há relação entre a experiência na função e o conhecimento do custo de capital de terceiros, $H_{1}$ : Há relação entre a experiência na função e o conhecimento do custo de capital de terceiros. 


\section{RESULTADOS OBTIDOS}

\subsection{Análise Descritiva}

A pesquisa envolveu um estudo empírico com 27 empresas pertencentes a 10 setores da economia. Das 27 empresas pesquisadas, 20 são pequenas e sete são médias, segundo critério de número de funcionários estabelecido pelo SEBRAE e adotado na presente pesquisa; 10 empresas estão constituídas sob a forma de sociedade anônima (S/A) e 17 sob a forma de sociedade limitada (LTDA). As maiores empresas da amostra (empregando acima de 320 funcionários) pertencem aos setores: têxtil (um caso), fabricação de edição, impressão e reprodução de gravações (um caso) e fabricação de equipamentos médico-hospitalares (um caso). O Quadro 1 descreve o perfil da amostra

Quadro 1 - Perfil da Amostra por Setor e Número de Empregados

\begin{tabular}{|c|c|c|c|c|}
\hline \multirow{2}{*}{ Setor } & \multicolumn{3}{|c|}{ Número de empregados } & \multirow{2}{*}{ Total } \\
\hline & De 20 a 120 & De 121 a 220 & De 321 a 499 & \\
\hline Fabricação de produtos alimentícios e bebidas & 3 & 2 & & $\overline{5}$ \\
\hline fabricação de produtos têxteis & 1 & 1 & 1 & 3 \\
\hline Fabricação de papel e celulose & 1 & & & 1 \\
\hline Fabricação de edição, impressão e repordução de gravações & 4 & & 1 & 5 \\
\hline Fabricação de artigos de borracha e plástico & 3 & & & 3 \\
\hline Fabricação de produtos minerais não-metálicos & & 1 & & 1 \\
\hline Fabricação de equipamentos médico-hospitalares & 1 & & 1 & 2 \\
\hline Fabricação de produtos de metal & 5 & & & 5 \\
\hline Fabricação de produtos químicos & 1 & & & 1 \\
\hline Fabricação de artefatos de couro e calçados & 1 & & & 1 \\
\hline Total & 20 & 4 & 3 & 27 \\
\hline
\end{tabular}

Fonte: Elaboração própria

O custo de capital é uma variável de fundamental importância para a determinação da estrutura ótima de capital. Este conteúdo foi amplamente discutido no referencial teórico da presente pesquisa. Verificou-se que o custo do capital é importante tanto para as decisões de investimento, como para as decisões de financiamento, logo, funciona como a base para a tomada de decisões financeiras. Desta forma, procurou-se perceber o nível de importância dada ao custo do capital (próprio e de terceiros) das empresas, bem como sua forma de mensuração.

Ao todo foram entrevistadas 27 pessoas, todas ligadas diretamente às decisões financeiras das empresas pesquisadas. Das 27 pessoas, 12 ocupavam o cargo de gerência e 15 de diretoria financeira. Apenas duas pessoas eram do sexo feminino e ambas ocupantes do cargo de gerência, ou seja, ocupando o cargo de diretoras financeiras, constatou-se apenas 
homens. 10 pessoas tinham de 41 a 50 anos, seis de 51 a 60 anos e cinco acima de 60 anos, isto é, $78 \%$ das pessoas entrevistadas tinham acima de 40 anos de idade. Aliado a isto, 74\% dos entrevistados possuíam mais de 10 anos de experiência na área financeira.

Com relação ao grau de instrução, três pessoas possuíam apenas o ensino fundamental, sete o ensino médio e 17 nível superior. Dos entrevistados que possuíam nível superior, sete tinham formação em contabilidade, dois em economia, dois em administração, quatro em engenharia, um em direito e um em matemática. Constatou-se, também, que das pessoas que tinham formação em contabilidade, três tinham também outra formação, sendo uma em economia, uma em administração e uma em direito. O Gráfico 1 apresenta a formação das pessoas entrevistadas.

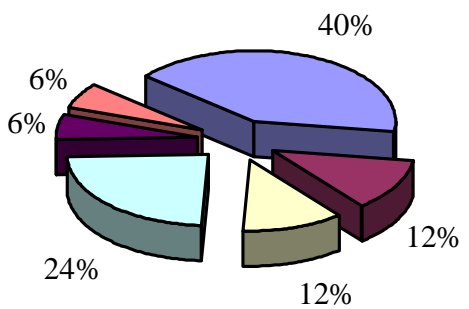

$\square$ Contabilidade
$\square$ Economia
$\square$ Administração
$\square$ Engenharia
$\square$ Direito
$\square$ Matemática

Gráfico 1 - Formação dos Entrevistados

Fonte: Elaboração própria

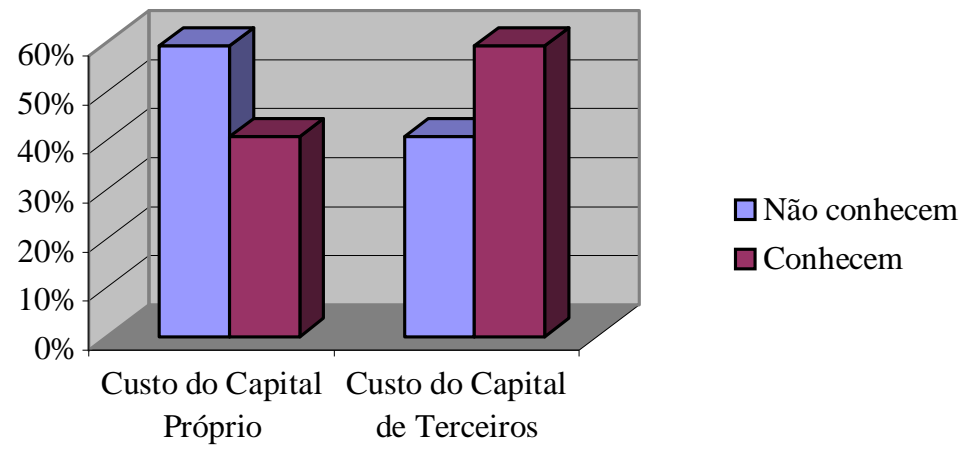

Gráfico 2 - Percepção dos Gestores Financeiros Quanto ao Custo do Capital Próprio e de Terceiros

Fonte: Elaboração própria 
O Gráfico 2 retrata a percepção dos entrevistados quanto ao custo do capital. Constatou-se que $60 \%$ dos entrevistados declararam não conhecer o custo do capital próprio (Gráfico 2). Os demais (40\%) relataram conhecer e o mensuravam das seguintes formas: Taxa mínima de rentabilidade exigida, mensurada pelo o custo de oportunidade perdida (cinco casos); Duas empresas mensuravam o custo do capital próprio a partir do sistema de contabilidade de custos. Em uma delas, este custo é revisado periodicamente (de quatro em quatro meses) por uma empresa de consultoria; Taxa mínima de mercado mais custo de oportunidade (dois casos); Custo do capital de terceiros mais $30 \%$ de lucro (dois casos).

Eid Júnior (1996), ao estudar o comportamento do custo de capital de empresas brasileiras, encontrou resultado semelhante ao exposto, revelando que $45 \%$ das empresas pesquisadas utilizam o retorno exigido pelos investidores como custo do capital próprio. Já no trabalho de Graham e Harvey (2001), 73,5\% das empresas estudadas utilizam o CAPM. No entanto, os autores revelam que as grandes empresas são mais propensas a utilizar o CAPM do que as pequenas empresas. As pequenas empresas são inclinadas para utilizar a taxa mínima de rentabilidade exigida pelos investidores, resultado semelhante ao aqui exposto.

Em uma das empresas pesquisadas, o entrevistado foi categórico em afirmar que o capital próprio não é oneroso para a empresa, isto é, não tem custo. Sabe-se que o capital, como todo fator de produção, tem um custo, quer seja ele próprio ou de terceiros. "A consideração do custo do capital próprio como sendo nulo é algo insustentável conceitualmente, é cegueira que parece nos pegar de nascença” (MARTINS, 2000, p.33).

No que diz respeito ao custo do capital de terceiros, $40 \%$ dos entrevistados relataram não o conhecer. Os demais $(60 \%)$ declararam conhecer e foram unânimes em afirmar que o custo do capital de terceiros é explícito e já vem definido pelas instituições financeiras, em seus respectivos contratos.

Além de averiguar o conhecimento do custo de capital, próprio e de terceiros, por parte dos entrevistados, foram realizados alguns cruzamentos, entre a percepção dos entrevistados e o cargo que ocupavam, formação, experiência na função, sexo, idade e tempo da empresa no mercado.

Dos gestores financeiros que declararam conhecer o custo do capital próprio, dois eram gerentes e nove diretores financeiros, ou seja, dos gestores que afirmaram conhecer o custo de capital próprio, $82 \%$ ocupavam o cargo de diretor. Quanto ao custo do capital de terceiros, quatro eram gerentes e 12 diretores financeiros, ou seja, $75 \%$ dos gestores que afirmaram conhecer o custo do capital de terceiros ocupavam o cargo de diretoria. Portanto, a 
maioria afirmou não conhecer o custo do capital próprio e de terceiros, porém, dos que relataram conhecer, grande parte ocupava o cargo de diretoria (Gráfico 3).

Dos gestores financeiros que afirmaram conhecer o custo do capital próprio, três possuíam ensino fundamental, um ensino médio e sete ensino superior. Dos sete que possuíam o ensino superior, dois tinham formação em contabilidade, um em economia, um em administração, dois em engenharia e um em direito. Quanto ao conhecimento do custo do capital de terceiros, três tinham ensino fundamental, três ensino médio e 10 ensino superior (Gráfico 4). Dos 10 que possuíam o ensino superior, dois tinham formação em contabilidade, dois em economia, um em administração, dois em engenharia, um em direito e um em matemática. Ressalta-se que um gestor tinha formação em contabilidade e direito, dos que relataram conhecer o custo do capital de terceiros. Logo, dos que afirmaram conhecer o custo do capital próprio e de terceiros, a maioria tinha formação em contabilidade ou engenharia.

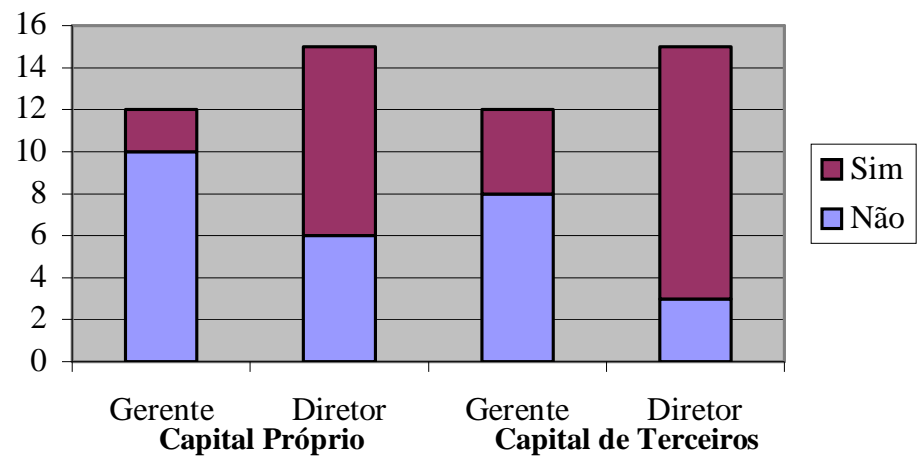

Gráfico 3 - Percepção dos Gestores quanto ao Custo do Capital X Cargo Ocupado Fonte: Elaboração Própria

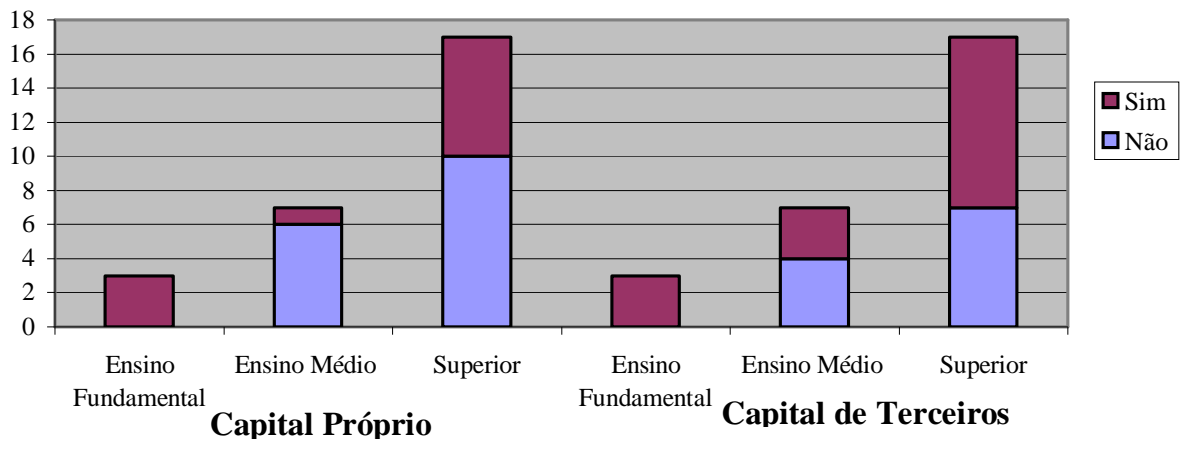

Gráfico 4 - Percepção dos Gestores quanto ao Custo do Capital X Formação 
Fonte: Elaboração Própria

Percebeu-se pela análise do Gráfico 3 que, dos entrevistados que declararam conhecer o custo do capital próprio e de terceiros, grande parte ocupava o cargo de diretoria. No entanto, as pessoas que ocupavam o cargo de gerência eram mais instruídas do que as que ocupavam o cargo de diretoria, principalmente nas empresas de menor porte, conforme retrata o Quadro 2. Uma justificativa para tal fato é que, na maioria das empresas pesquisadas, o diretor era o dono da empresa que, sem uma formação sólida em finanças, contratava profissionais para exercer essa função (isso no caso das médias empresas, pois nas pequenas o dono era o próprio diretor financeiro, acumulando ainda várias outras funções),. Eid Júnior (1996) também constatou esse desconhecimento das técnicas existentes na teoria financeira, apesar do nível de instrução dos entrevistados, quase sempre de nível superior ou com pósgraduação.

Quadro 2 - Cargo Ocupado x Grau de Instrução

\begin{tabular}{|l||c|c|c|c|}
\hline \multirow{2}{*}{ Cargo que ocupa } & \multicolumn{3}{c|}{ Grau de instrução } & \multirow{2}{*}{ Total } \\
\cline { 2 - 5 } & Ensino Fundamental & Ensino Médio & Superior & \\
\hline \hline Gerente Financeiro & - & 2 & 10 & 12 \\
Diretor Financeiro & 3 & 5 & 7 & 15 \\
\hline \hline Total & 3 & 7 & 17 & 27 \\
\hline
\end{tabular}

Fonte: Elaboração Própria

Quanto à experiência na função e o conhecimento do custo do capital próprio, dos que afirmaram conhecê-lo, dois tinham até cinco anos de experiência na função, um tinha entre 11 e 15 anos, três de 16 a 20 anos, três de 26 a 30 anos e dois acima de 30 anos. No que diz respeito ao custo do capital de terceiros, três tinham até cinco anos de experiência na função, dois tinham entre 11 e 15 anos, três de 16 a 20 anos, um de 21 a 25 anos, quatro de 26 a 30 anos e três acima de 30 anos. Percebe-se, portanto, que grande parte dos entrevistados que declarou conhecer o custo de capital próprio e de terceiros tinha mais de 15 anos de experiência na função de gerente ou diretor financeiro. (Quadro 3) 
Quadro 3 - Percepção dos Gestores quanto ao Custo do Capital X Experiência na Função

\begin{tabular}{|l||c||c|c|c|c||c|}
\hline \multirow{2}{*}{ Experiência na função } & \multicolumn{2}{|c|}{ Conhece o custo do capital de terceiros } & \multirow{2}{*}{ Total } & \multicolumn{2}{c|}{ Conhece o custo do capital próprio } & \multirow{2}{*}{ Total } \\
\cline { 2 - 3 } & Não & Sim & & Não & Sim & \\
\hline \hline Até 5 anos & 4 & 3 & 7 & 5 & 2 & 7 \\
De 6 a 10 anos & 1 & - & 1 & 1 & - & 1 \\
De 11 a 15 anos & 2 & 2 & 4 & 3 & 1 & 4 \\
De 16 a 20 anos & 2 & 3 & 5 & 2 & 3 & 5 \\
De 21 a 25 anos & 2 & 1 & 3 & 3 & - & 3 \\
De 26 a 30 anos & - & 4 & 4 & 1 & 3 & 4 \\
Acima de 30 anos & - & 3 & 3 & 1 & 2 & 3 \\
\hline Total & 11 & 16 & 27 & 16 & 11 & 27 \\
\hline
\end{tabular}

Fonte: Elaboração Própria

Quanto ao sexo e o conhecimento do custo do capital próprio e de terceiros, todos os entrevistados que afirmaram conhecer o custo do capital próprio e de terceiros eram do sexo masculino.

No que diz respeito à idade e conhecimento do custo do capital próprio, dos que afirmaram conhecê-lo, um tinha entre 20 e 30 anos de idade, um de 31 a 40, três de 41 a 50, três de 51 a 60 e três acima de 60 anos de idade. Quanto ao custo do capital de terceiros, um tinha entre 20 e 30 anos de idade, dois de 31 a 40, quatro de 41 a 50, cinco de 51 a 60 e quatro acima de 60 anos de idade. Portanto, percebe-se que a maioria que declarou conhecer o custo do capital próprio e de terceiros tinha acima de 40 anos de idade. (Quadro 4)

Quadro 4 - Percepção dos Gestores quanto ao Custo do Capital X Idade

\begin{tabular}{|l|c|c||c||c|c|c|}
\hline \multicolumn{1}{|c|}{ Idade } & \multicolumn{2}{c|}{ Conhece o custo do capital próprio } & \multirow{2}{*}{ Total } & Conhece o custo do capital de terceiros & \multirow{2}{*}{ Total } \\
\cline { 2 - 3 } & Não & Sim & & Não & Sim & \\
\hline \hline De 20 a 30 anos & 1 & 1 & 2 & 1 & 1 & 2 \\
De 31 a 40 anos & 3 & 1 & 4 & 2 & 2 & 4 \\
De 41 a 50 anos & 7 & 3 & 10 & 6 & 4 & 10 \\
De 51 a 60 anos & 3 & 3 & 6 & 1 & 5 & 6 \\
Acima de 60 anos & 2 & 3 & 5 & 1 & 4 & 5 \\
\hline \hline Total & 16 & 11 & 27 & 11 & 16 & 27 \\
\hline
\end{tabular}

Fonte: Elaboração Própria 
Realizou-se, também, o cruzamento entre a percepção dos entrevistados com o tempo da empresa no mercado. Observou-se que, dos entrevistados que afirmaram conhecer o custo do capital próprio, três trabalhavam em empresas com até 10 anos de existência, dois em empresas entre 11 e 20 anos, cinco em empresas de 21 a 30 anos e um em empresas com acima de 41 anos de existência. No que diz respeito ao custo do capital de terceiros, três trabalham em empresas com até 10 anos de existência, quatro em empresas entre 11 e 20 anos, sete em empresas de 21 a 30 anos e dois em empresas com acima de 41 anos de existência. Portanto, a maioria que afirmou conhecer o custo do capital próprio e de terceiros trabalhava em empresas que têm 21 anos ou mais de mercado. (Quadro 5)

Quadro 5 - Percepção dos Gestores quanto ao Custo do Capital X Tempo no Mercado

\begin{tabular}{|c|c|c|c|c|c|c|}
\hline \multirow{2}{*}{ Tempo } & \multicolumn{2}{|c|}{ Conhece o custo do capital próprio } & \multirow{2}{*}{ Total } & \multicolumn{2}{|c|}{ Conhece o custo do capital de terceiros } & \multirow{2}{*}{ Total } \\
\hline & Não & Sim & & 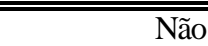 & Sim & \\
\hline Até 10 anos & 3 & 3 & 6 & 3 & 3 & 6 \\
\hline De 11 a 20 anos & 4 & 2 & 6 & 2 & 4 & 6 \\
\hline De 21 a 30 anos & 6 & 5 & 11 & 4 & 7 & 11 \\
\hline De 31 a 40 anos & 1 & - & 1 & 1 & - & 1 \\
\hline Acima de 41 anos & 2 & 1 & 3 & 1 & 2 & 3 \\
\hline Total & 16 & 11 & 27 & 11 & 16 & 27 \\
\hline
\end{tabular}

Fonte: Elaboração Própria

Os entrevistados foram indagados, ainda, podendo optar por mais de uma resposta, sobre os fatores que mais têm afetado a rentabilidade de suas empresas. Os mais relatados foram: a alta concorrência (67\%), as taxas de juros dos financiamentos (41\%) e o custo do capital (35\%). (Gráfico 5)

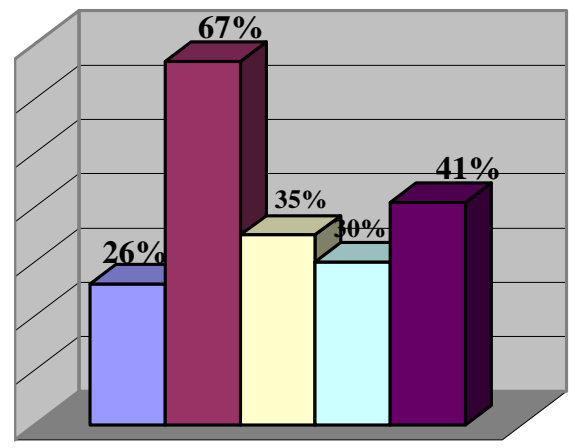

Falta de liquidez

Alta concorrência

$\square$ Custo do capital

$\square$ Políticas econômicas

taxas de juros sobre financiamentos

Gráfico 5 - Fatores que mais têm Afetado a Rentabilidade das Empresas

Fonte: Elaboração própria

Percebe-se que, segundo os entrevistados, os fatores que mais têm afetado a rentabilidade das empresas dizem respeito a fatores associados ao custo do capital próprio e 
de terceiros (35\% custo do capital e $41 \%$ taxas de juros sobre os financiamentos, ou seja, custo do capital de terceiros). A partir desses resultados, confrontou-se a percepção dos entrevistados com os fatores que mais têm afetado a rentabilidade da empresa.

Observou-se que, oito entrevistados afirmaram ser o custo do capital um dos fatores que mais tem afetado a rentabilidade das empresas, dos quais seis declararam não conhecer o custo do capital próprio. Quanto ao custo do capital de terceiros, dos oito que afirmaram ser o custo do capital um dos fatores que mais tem afetado a rentabilidade das empresas, três relataram não conhecer o custo do capital de terceiros. Portanto, notou-se que, apesar do custo do capital ser um dos fatores que mais tem afetado a rentabilidade das empresas pesquisadas, a grande maioria declarou não conhecer.

\subsection{Análise das Hipóteses}

Tendo em vista que nossa amostra encontra-se no intervalo de 20 a 40 e que existe freqüência esperada inferior a 5, recorreu-se ao teste exato de Fisher, para análise das hipóteses, conforme sugere Siegel (1975).

Conforme o resultado do Teste Exato de Fischer, presente no Quadro 6, constata-se que o nível de significância foi de 0,047, inferior ao nível crítico. Portanto, rejeita-se a hipótese nula em favor da hipótese alternativa e conclui-se que há relação entre o cargo ocupado e conhecimento do custo de capital próprio, ao nível de significância de $5 \%$.

Conforme Quadro 7, constata-se que o nível de significância foi de 0,022, inferior ao nível crítico. Portanto, rejeita-se a hipótese nula em favor da hipótese alternativa e conclui-se que há relação entre o cargo ocupado e conhecimento do custo de capital de terceiros, ao nível de significância de $5 \%$.

De acordo com o Quadro 8, constata-se que o nível de significância foi de 1,000, superior ao nível crítico. Portanto, a hipótese nula não pode ser rejeitada e conclui-se que não há relação entre possuir curso superior e conhecimento do custo de capital próprio. Constatouse o mesmo nível de significância para a relação entre possuir curso superior e conhecimento do custo do capital de terceiros (Quadro 9), não se podendo rejeitar a hipótese nula, concluindo-se, portanto, que não há relação entre as duas variáveis, ao nível de significância de $5 \%$.

Observa-se no Quadro 10 que o nível de significância foi de 0,687, superior ao nível crítico. Portanto, a hipótese nula não pode ser rejeitada e conclui-se que não há relação entre 
possuir experiência na função e conhecimento do custo de capital próprio, ao nível de significância de 5\%. Quanto ao conhecimento do custo de capital de terceiros, também não se pode rejeitar a hipótese nula, uma vez que o nível de significância obtido foi de 0,124 , superior ao nível crítico, concluindo-se, portanto, que não existe relação entre experiência na função e conhecimento do custo de capital de terceiros, ao nível de significância de $5 \%$. (Quadro 11)

Quadro 6 - Cargo Ocupado x Conhecimento do Custo de Capital Próprio

\begin{tabular}{|ll|c|c|c|}
\hline \multirow{2}{*}{} & \multirow{2}{*}{ Frequência } & \multicolumn{2}{|c|}{ Conhece o custo do capital de terceiros } & \multirow{2}{*}{ Total } \\
\cline { 3 - 5 } & Gerente financeiro Observada & 8,0 & Sim & \\
\hline \multirow{3}{*}{ Cargo que ocupa } & Esperada & 4,9 & 4,0 & 12,0 \\
& & 3,0 & 7,1 & 12,0 \\
& Diretor financeiro Observada & 6,1 & 12,0 & 15,0 \\
& & 11,0 & 8,9 & 15,0 \\
\cline { 2 - 5 } & Esperada & 16,0 & 27,0 \\
\hline
\end{tabular}

Nível de significância do Teste Exato de Fisher $=0,047$

Fonte: Elaboração Própria

Quadro 7 - Cargo Ocupado x Conhecimento do Custo de Capital de Terceiros

\begin{tabular}{|ll|c|c|c|}
\hline \multirow{2}{*}{} & \multirow{2}{*}{ Frequência } & \multicolumn{2}{|c|}{ Conhece o custo do capital próprio } & \multirow{2}{*}{ Total } \\
\cline { 3 - 5 } & \multicolumn{2}{l}{ Não } & Sim & \\
\hline \multirow{3}{*}{ Cargo que ocupa } & Gerente financeiro Observada & 10,0 & 2,0 & 12,0 \\
& Esperada & 7,1 & 4,9 & 12,0 \\
\cline { 2 - 5 } & Diretor financeiro Observada & 6,0 & 9,0 & 15,0 \\
& & 8,9 & 6,1 & 15,0 \\
\hline & & 16,0 & 11,0 & 27,0 \\
\hline
\end{tabular}

Nível de significância do Teste Exato de Fisher $=0,022$

Fonte: Elaboração Própria

Quadro 8 - Possuir Curso Superior x Conhecimento do Custo de Capital Próprio

\begin{tabular}{|c|c|c|c|c|c|}
\hline \multirow{2}{*}{\multicolumn{3}{|c|}{ Frequência }} & \multicolumn{2}{|c|}{ Conhece o custo do capital próprio } & \multirow{2}{*}{ Total } \\
\hline & & & Não & Sim & \\
\hline \multirow{4}{*}{$\begin{array}{l}\text { Possuui } \\
\text { Curso Superior? }\end{array}$} & Não & Observada & 6,0 & 4,0 & 10,0 \\
\hline & & Esperada & 5,9 & 4,1 & 10,0 \\
\hline & Sim & Observada & 10,0 & 7,0 & 17,0 \\
\hline & & Esperada & 10,1 & 6,9 & 17,0 \\
\hline \multicolumn{3}{|l|}{ Total } & 16,0 & 11,0 & 27,0 \\
\hline
\end{tabular}

Nível de significância do Teste Exato de Fisher $=1,000$

Fonte: Elaboração Própria 
Quadro 9 - Possuir Curso Superior x Conhecimento do Custo de Capital de Terceiros

\begin{tabular}{|lll|c|c|c|}
\hline \multicolumn{2}{|l|}{ Frequência } & \multicolumn{2}{c|}{ Conhece o custo do capital de terceiros } & \multirow{2}{*}{ Total } \\
\cline { 3 - 6 } & & Não & Sim & \\
\hline Possuui & Não & Observada & 4,0 & 6,0 & 10,0 \\
Curso Superior? & & Esperada & 4,1 & 5,9 & 10,0 \\
& & Observada & 7,0 & 10,0 & 17,0 \\
& \multirow{2}{*}{ Sim } & Esperada & 6,9 & 10,1 & 17,0 \\
\hline & & 11,0 & 16,0 & 27,0 \\
\hline
\end{tabular}

Nível de significância do Teste Exato de Fisher $=1,000$

Fonte: Elaboração Própria

Quadro 10 - Experiência na Função x Conhecimento do Custo de Capital Próprio

\begin{tabular}{|lll|c|c|c|}
\hline \multirow{2}{*}{} & \multirow{2}{*}{ Frequência } & \multicolumn{2}{|c|}{ Conhece o custo do capital próprio } & \multirow{2}{*}{ Total } \\
\cline { 5 - 6 } & & Não & Sim & \\
\hline \multirow{3}{*}{ Experiência } & Até 20 anos & Observada & 11,0 & 6,0 & 17,0 \\
na Função & & Esperada & 10,1 & 6,9 & 17,0 \\
& Acima de 20 anos & Observada & 5,0 & 5,0 & 10,0 \\
& & Esperada & 5,9 & 4,1 & 10,0 \\
\hline Total & & 16,0 & 11,0 & 27,0 \\
\hline
\end{tabular}

Nível de significância do Teste Exato de Fisher $=0,687$

Fonte: Elaboração Própria

Quadro 11 - Experiência na Função x Conhecimento do Custo de Capital de Terceiros

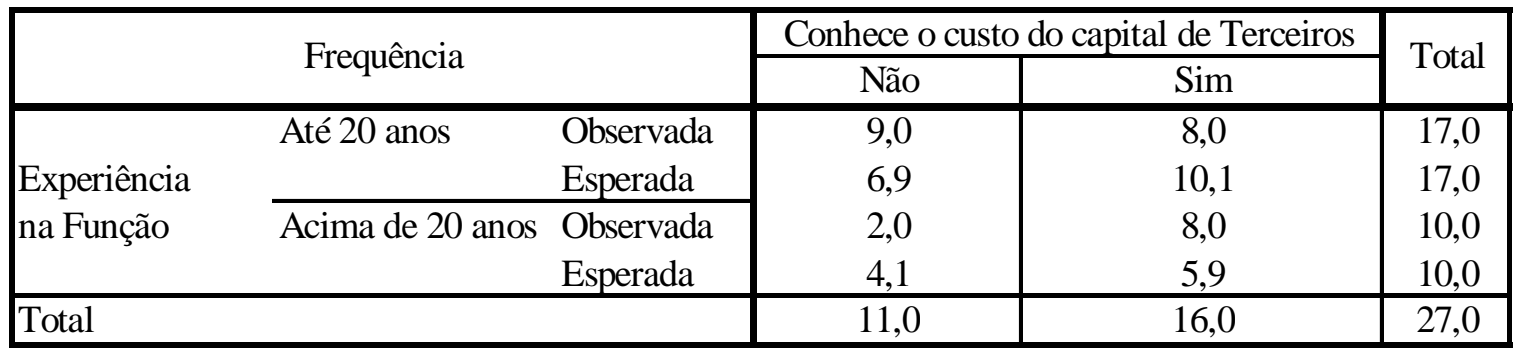

Nível de significância do Teste Exato de Fisher $=0,124$

Fonte: Elaboração Própria

\section{CONCLUSÃO}

Este trabalho teve por objetivo analisar o grau de percepção dos gestores financeiros das pequenas e médias quanto ao custo de capital. 
Constatou-se que a maioria dos entrevistados declarou não conhecer o custo do capital próprio. Dos que afirmaram conhecer mensuram, em sua maioria, como a taxa mínima de rentabilidade exigida, mensurada pelo custo de oportunidade perdida. No que diz respeito ao custo do capital de terceiros, grande parte relatou conhecer e foi unânime em afirmar que o custo do capital de terceiros é explícito e já vem definido pelas instituições financeiras, em seus respectivos contratos.

Constatou-se que, dos gestores entrevistados que afirmaram conhecer o custo de capital próprio e de terceiros, grande parte ocupava o cargo de diretoria, possuía formação em contabilidade ou engenharia, tinham mais de 15 anos de experiência na função, tinham acima de 40 anos de idade, trabalhavam em empresas com 21 anos ou mais de existência no mercado e eram do sexo masculino. Constatou-se, também, que, apesar do custo do capital ser um dos fatores que mais tem afetado a rentabilidade das empresas pesquisadas, a grande maioria afirmou não o conhecer. Aliado a isto, acrescenta-se o fato do custo de capital representar a base para tomada de decisões financeiras.

Constatou-se, também, que existe relação entre o cargo ocupado e o conhecimento do custo do capital próprio e de terceiro, e que não existe relação entre possuir curso superior, bem como experiência na função, e o conhecimento do custo de capital próprio e de terceiros, ao nível de significância de $5 \%$.

\section{REFERÊNCIAS}

ALCANTARA, J. C.G. O modelo de avaliação de ativos (Capital Asset Pricing Model) Aplicações. Revista de Administração de Empresa. Rio de Janeiro, v. 21, n. 1, p. 55-65, 1981.

ARCHER, S. H.; D’AMBROSIO, C. A. Administração Financeira. Teoria e Aplicação. São Paulo: Atlas, 1969.

ARDITTI, F. D. The weighted average cost of capital: some questions on its definition, interpretation, and use. Journal of Financial, v.28, p. 1001-1007, 1973.

ASSAF NETO, A. Finanças corporativas e valor. São Paulo: Atlas, 2003.

ASSAF NETO, A.; MARTINS, E.. Administração Financeira: as finanças sob condições inflacionárias. São Paulo: Atlas, 1986. 
BONESS, J. A.. A pedagogic note on the cost of capital. The Journal of Finance, v.19, p. 99-106, 1964.

BRAGA, R. Fundamentos e técnicas de administração financeira. São Paulo: Atlas, 1995.

BRASIL. Leis 6.404, de 15 de dezembro de 1976. Dispõe sobre as sociedades por ações. Lei das S.A. São Paulo: Atlas, 1995.

BRIGHAM, E. F.; HOUSTON, J. F. Fundamentos da moderna administração financeira. Rio de Janeiro: Campus, 1999.

COPELAND, T.; KOLLER, T. e MURRIN, J. Avaliação de empresas - "valuation": calculando e gerenciando o valor das empresas. São Paulo: Makron Books, 2002.

DAMODARAM, A. Avaliação de Investimentos: ferramentas e técnicas para determinação do valor de qualquer ativo. Rio de Janeiro: Qualitymark, 1997.

EID JÚNIOR, W. Custo e estrutura de capital: o comportamento das empresas brasileiras. Revista de Administração de Empresas, São Paulo, v.36, n.4, p. 51-59, out/nov/dez 1996.

GITMAN, L. J. Princípios de administração financeira. São Paulo: Harbra, 1997.

GRAHAM, J. R.; HARVEY, C. R. The theory and practice of corporate finance: evidence from the field. Journal of Financial Economics, v.60, p. 187-243, 1999.

LAMEIRA, V. de J. A estrutura de capital das sociedades anônimas. Rio de Janeiro: Forense Universitária, 2001.

LEITE, J. A. A. Economia financeira. (mimeografado), 2000.

LINTNER, J. The valuation of risk assets and the selection of risky investments in stock portfolios and capital budgets. Review of Economics and Statistics, p. 13-37, 1965. 
MACHADO, M. A. V. Determinantes da estrutura de capital das pequenas e médias empresas industriais da cidade de João Pessoa/PB. 2002, 221 f. Dissertação (Mestrado em administração) - Universidade Federal da Paraíba, João Pessoa, 2002.

MARTINS, E. Avaliação de Empresas: da Mensuração Contábil à Econômica. In Caderno de Estudos, São Paulo: Fipecafi e EAC/FEA/USP, n.24, v.13, p.28-37, jul./dez. 2000.

PENTEADO, M. A. de B.; FAMÁ, R. . Será que o beta que temos e o beta que queremos?. Caderno de Pesquisa em Administração, São Paulo, v. 9, n. 3, jul/set de 2002.

PINDYCK, R. S.; RUBINFELD, D. L.. Microeconomia. São Paulo: Makron Books, 1994.

ROSS, S. A.; WESTERFIELD, R. W.; JAFFE, J. F. Corporate Finance. New York: McGraw-Hill, 2001.

SANVICENTE, A. S.; MINARD, A. M. A. Determinação do custo do capital do acionista no Brasil. Instituto Brasileiro de Mercado de Capitais. 30 de abril de 1999.

SANVICENTE, A. Z. Administração financeira. 3. ed. São Paulo: Atlas, 1997.

SHARPE, W. F.. Capital asset prices: a theory of market equilibrium under conditions of risk. Journal of Financial, v.19, p. 425-442, 1964.

SIEGEL, S. Estatística Não-paramétrica para as Ciências do Comportamento. São Paulo: Mc Graw- Hill, 1975.

SILVA, M. A. V. R. Alguns problemas para estimação do custo de capital próprio no $\begin{array}{lllll}\text { mercado } & \text { acionário } & \text { brasileiro. } & \text { Disponível } & \text { em }\end{array}$ http://www.unitau.br/nupes/artigos/custo_capital.htm. Acesso em março de 2005.

TREYNOR, J. Toward a theory of the market value of risky assets. Artigo não publicado, 1961.

VAN HORNE, J. C. Financial managment and policy. 3 ed. Englewood Cliffs:Prenticehall, 1974. 
VAN HORNE, J. C. Política e administração financeira. São Paulo: Livros Técnicos e Científicos. v. 1, 1979.

VERGARA, S. C. Projetos e relatórios de pesquisa em administração. 3. ed. São Paulo: Atlas, 2000.

WESTON, J. F.; BRIGHAM, E. F. Fundamentos da administração financeira. São Paulo: Makron Books, 2000.

Artigo recebido em 01/10/2005 e aceito para publicação em 07/08/2005 